\title{
Preference for Online Social Interaction: a Research on the Potential Influencing Factors
}

\author{
Jiang Song \\ School of Economics and Management \\ Nanjing University of Science and Technology \\ Nanjing, China \\ songjiang1989@163.com
}

\author{
Junfeng Jiang \\ Department of Sociology \\ Wuhan University \\ Wuhan, China \\ junfeng_1994@163.com
}

\begin{abstract}
Objective] This paper aims to identify the potential factors leading to a preference for online social interaction to offline interaction. [Methods] Based on an online survey $(\mathrm{N}=233)$ and a SEM analysis, [Results] findings show that: 1) compared to those who were good at face-toface communication, individuals who were not might prefer online social interaction much more; 2 ) the higher the popularity level of preference for online social interaction among the crowd around an individual, the more he was likely to show similar preference; 3 ) compared to those with a limited level of involvement in online social interaction, individuals with a higher level would develop a stronger preference for online social interaction; 4) compared to those with a higher level of satisfaction with their current offline contacts, individuals with a lower level of satisfaction were more likely to prefer online social interaction. [Conclusion] The findings will give some help for users and designers of social networking sites.
\end{abstract}

Keywords- Online Social Interaction; Preference for Online Social Interaction; Computer Mediated communication; Preference; Internet

\section{INTRODUCTION}

The instant communication software and social network sites are more and more popular over the last decade (Wittkower, 2010) [1]. It has been suggested that an "online community" has developed, with increasing numbers of people using online services to communicate and connect (Boyd \& Ellison, 2008) [2], which has a deep effect on people's daily social communication (Cheung \& Lee, 2010) [3]. The development of the network not only gradually changed the whole world, but also gradually changed the way of people's social communication. This web-based communication provides a new perspective for the study of the relationship between people (Caplan, 2001) [4], and the research is particularly important compared to the prior research on face-to-face communication (FTFC) (Caplan, 2003) [5]. The max-utility behavior is considered as the individual's preference in modern economics area. While in psychology area, preference is the attitude or performance of the outpouring tendency and it is the judgments between two or more options (Crites, 1994) [6]. Preference for online social interaction (POSI) is a cognitive individual-difference construct characterized by beliefs that one is safer, more efficacious, and more confident with online interpersonal interaction than with face-to-face interaction (Caplan, 2003) [5].
One communication phenomenon of great interest, and subject to much debate, in both popular and academic literature is the association between Internet use and psychosocial health. Research from a variety of disciplines, including communication, reflects a growing concern with compulsive Internet use and its potential ill effects (Beard \& Wolf, 2001; Davis, 2001) [7] [8]. Recently, researchers had their attentions on the behaviors of social networking site users. Ridings and Gefen (2004) [9] had a survey on 27 virtual communities of five different types and found the main reasons about online social interaction were friendships, information exchanging, seeking social support and entertainment. In China, a similar survey was done between Chinese netizens (Xie \& Zhang, 2011) [10]. Some studies were about the relationship between personal self-esteem (Fioravanti et al., 2012) [11], emotional intelligence (Casale, et al., 2013) [12] and preference for online social interaction. There has been a recent surge in research investigating the use of Social Networking Sites. Studies include examination of motivations for use (Bonds-Raacke \& Raacke, 2010) [13], factors associated with self-disclosure (Ryan, 2011) [14] and social connectedness (Rachel, et al., 2013) [15].

Other researchers thought the easy use and convenience were the reasons that made people prefer to connect online. They attentions were on improving the algorithms or models of social networking sites (Zhang \& Li, 2011; Yu, 2012; Deng et al., 2012; Tang \& Zhang, 2013) [16-19].

However, few studies have focused on what factors affect people's preference for online social interaction. In this study some internet users were surveyed, and potential factors leading to preference for virtual social interaction online over offline interaction were examined. Then four hypotheses were developed to examine potential factors leading to preference for social interaction online and finally the results of hypothesis were discussed.

\section{HYPOTHESES}

\section{A. Face-to-Face Communication and Preference for Online Social Interaction}

In daily life, some people are not good at face-to-face communication with others, even with their own relatives and friends. However, when they are online, they can express fluently. They lack the face to face communication skills, and communication barriers exist in the mind. When 
communicating with people face to face, they feel a kind of social threat (Amichai-Hamburger \& Furnham, 2007; Caplan, 2005) [20-21]. Online social interaction does not require face to face immediately, so people will feel more secure and comfortable when they connect on the Internet (Caplan, 2006) [22].

Besides the communication skills, those who have no confidence about oral expressions or who is perfectionist may avoid face to face communication because of the limited time to considerate and reply. It is not a problem in the situations online, because it is not time-synchronization (Walther, 1996) [23]. One can also use the words, pictures, voice as well as videos to express himself/herself more easily and vividly. All above will improve the quality of the communications and increase the confidence. We therefore posit:

Hypothesis 1: Compared to those who are good at faceto-face communication, individuals who are not good at face-to-face communication will be more likely to prefer online social interaction.

\section{B. Surroundings and Preference for Online Social Interaction}

Learning ability allows a person to better adapt to the surrounding environment. Bandura (1977) [24] believed that if people observe others around do specific behavior, then they will also have this tendency and this self-learning ability is innate. In Hierarchy of Needs Theory, Maslow advanced in 1970, people have needs of belonging to a community and tend to be the same with the large groups around. This sense of belonging and tendency still exists in network environment. The environment here is not referring to the geographical environment, but the environment where people communicating. Baumister and Leary (1995) [25] identified substantial support for the hypothesized needs to belong, and argued that individuals develop and continue meaningful relationships and connections in order to experience a sense of belonging and enhance their wellbeing.

Klick and Parisi (2008) [26] thought that individuals' preferences change slowly and are affected by surroundings. Someone did or did not does not use online connection is much depend on others in the project team (Bagozzi, 2007) [27]. We therefore posit:

Hypothesis 2: Preference for online social interaction is affected by surrounding people; the higher level of online social interaction penetration in surrounding people is, the more they will be likely to prefer online social interaction.

\section{Depth of Online Social Interaction and Preference for Online Social Interaction}

The preference for online social interaction is a process. When people began to connect online, as time goes by, online social interaction becomes a part of people's life. Some of them have a deep online social interaction level: they need to work in a network group communication, chat with friends and family, record their feelings, and write articles. It seems that they have a strong preference for online social interaction as they are restless and apathetic all day when they leave the internet. Studies have found that excessive use of the internet may lead to a strong scene of online social interaction preference (Caplan, 2003) [5]. Preference for online social interaction and internet addiction are two concepts while some connections are between them. The deeper level of online social interaction individuals have, the more will avoid face to face communication (Lee and Stapinski, 2012; Caplan, 2010) [28][29]. So, will someone who has a deep level of online social interaction develop a strong preference for online social interaction? We therefore posit:

Hypothesis 3: Compared to those with a deeper level of online social interaction, individuals with a shallower level of online social interaction will develop a stronger preference for online social interaction.

\section{Satisfaction of Offline Social Interaction and Preference for Online Social Interaction}

Most relationships are not in air. Online and offline worlds are psychologically connected and felt and experienced as continuous spaces (Subrahmanyam \& Greenfield, 2008) [30]; so offline social relationships are expected to influence the way one communicates on the internet (Turner et al., 2006) [31]. Although real-world is not the same to the online social networking sites in structures and attributes, but still, to a certain extent, affects one's communications on the internet (Yu et al., 2012) [17]. Bell (2011) [32] had a study and showed that about $70 \%$ patients who were not satisfied with health care services went to online social groups to seek help. Some people can get better treated by others online than in reality, and a higher sense of satisfaction can be felt. It is obvious that when individuals cannot get what they want and feel unsatisfied, they will have a motive to change it and look for a "more satisfactory" way. We therefore posit:

Hypothesis 4: Compared to those with a higher level of satisfaction with their current offline contacts, individuals with a lower level of satisfaction with offline contacts will be more likely to prefer online social interaction.

Finally, the conceptual model on the influencing factors of preference for online social interaction is as Figure 1.

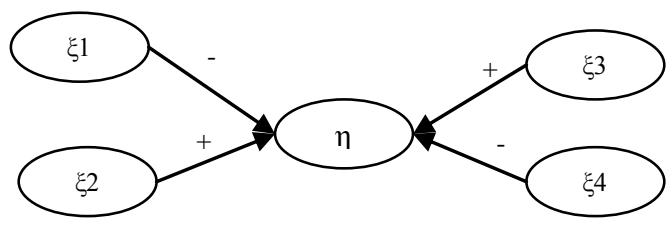

$\xi 1$ - Face to Face Communication, $\xi 2-$ Penetration in Surrounding People, $\xi 3$ - Depth of Online Social Interaction, $\xi 4$ - Satisfaction of Offline Social Interaction, $\eta$ - Preference for Online Social Interaction

Figure 1. Conceptual Model on the Influencing Factors of POSI

\section{METHOD}

\section{A. Participant Recruitment and Study Setting}

An online survey, posted on a commercial website, was conducted to verify the hypothesis presented earlier. All internet users could participate in the survey and were provided some cash prizes. The investigation cost 1 week time. After removed some bad samples ( 2 minutes <time or time > 15minutes), we finally got 233 samples.

In addition, information about respondents' demographic characteristics (age, gender and education) were obtained and included as control variables (Table 1). 
TABLE I. RESPONDENTS CHARACTERISTICS (N=233)

\begin{tabular}{|l|l|l|l|}
\hline \multirow{4}{*}{ Age } & & $N$ & $\%$ \\
\hline \multirow{5}{*}{ Gender } & $19-25$ & 36 & 15.5 \\
\cline { 2 - 4 } & $26-35$ & 148 & 63.5 \\
\cline { 2 - 4 } & $36-49$ & 45 & 19.3 \\
\cline { 2 - 4 } & $50-65$ & 4 & 1.7 \\
\hline \multirow{3}{*}{ Education } & male & 102 & 43.8 \\
\cline { 2 - 4 } & female & 131 & 56.2 \\
\cline { 2 - 4 } & Middle school or less & 6 & 2.6 \\
\cline { 2 - 4 } & High school & 11 & 4.7 \\
\cline { 2 - 4 } & College/university & 185 & 79.4 \\
\hline
\end{tabular}

\section{B. Measures}

All potential variables were contained by the 3 to 4 observing variables to ensure the validity. Questionnaire scale Likert scale with 7 options, from one (strongly disagree) to 7 (strongly agree). Table 2 shows the observing variables items.

TABLE II. OBSERVING VARIABLES ITEMS

\begin{tabular}{|c|c|}
\hline Potential variable & Observing variable \\
\hline $\begin{array}{l}\text { 1.Face to face } \\
\text { communication }\end{array}$ & $\begin{array}{l}\text { I feel embarrassed when I have a face to face } \\
\text { communication } \\
\text { I am shy when I have a face to face } \\
\text { communication. } \\
\text { I cannot express myself clearly when I have a } \\
\text { face to face communication. } \\
\text { I cannot express myself fluently when I have a } \\
\text { face to face communication. }\end{array}$ \\
\hline $\begin{array}{l}\text { 2. Penetration in } \\
\text { surrounding people }\end{array}$ & $\begin{array}{l}\text { People around me have social networking } \\
\text { accounts. } \\
\text { People around me use the internet platform to } \\
\text { convey notice, study materials, discuss the work, } \\
\text { etc. } \\
\text { People around me are very active on social } \\
\text { networks. }\end{array}$ \\
\hline $\begin{array}{l}\text { 3. Depth of online } \\
\text { social interaction }\end{array}$ & $\begin{array}{l}\text { I am very active on social networks. } \\
\text { I spend a lot of time on online social interaction. } \\
\text { I often use my mobile phone to visit social } \\
\text { network sites from time to time. } \\
\text { Online social interaction has become a very } \\
\text { important part in my life and I cannot leave it. }\end{array}$ \\
\hline $\begin{array}{l}\text { 4. Satisfaction of } \\
\text { offline social } \\
\text { interaction }\end{array}$ & $\begin{array}{l}\text { I can get the satisfaction I want when } \\
\text { communicating face to face. } \\
\text { It is harmonious when I connect with my family, } \\
\text { friends and classmates face to face. } \\
\text { I am very satisfied with face to face } \\
\text { communication }\end{array}$ \\
\hline $\begin{array}{l}\text { 5. Preference for } \\
\text { online social } \\
\text { interaction }\end{array}$ & $\begin{array}{l}\text { I will choose online more than offline when I } \\
\text { have something to talk with others. } \\
\text { I am happier and comfortable communicating } \\
\text { with people online than offline. } \\
\text { I prefer to online when online and offline both } \\
\text { are available. }\end{array}$ \\
\hline
\end{tabular}

\section{ANALYSIS AND RESULTS}

Visual PLS 1.04 and Spss 17.0 were used as statistical software. Some work had done before analyzing as variables 1 and 4 were reverse asking items. Loadings of every variable were above 0.7 , meaning the items had good convergent validity (see Table 3 ).

For each of the foregoing measures, averages were calculated to obtain a single score. The Composite Reliability (CR) was above 0.9, the Cronbach Alpha $(\alpha)$ was above 0.8 and the Average Variance Extracted (AVE) was above 0.7. A good the internal consistency was got (Table 3)
TABLE III. LOADINGS, CR, AVE AND ALPHA OF VARIABLES

\begin{tabular}{|c|c|c|c|c|c|c|c|}
\hline & \multicolumn{4}{|c|}{ Loadings } & \multirow{2}{*}{ CR } & \multirow{2}{*}{ AVE } & \multirow{2}{*}{ Alpha } \\
\hline & 1 & 2 & 3 & 4 & & & \\
\hline 1.FFC & 0.904 & 0.925 & 0.890 & 0.823 & 0.936 & 0.786 & 0.909 \\
\hline 2. PSP & 0.901 & 0.916 & 0.834 & - & 0.915 & 0.782 & 0.860 \\
\hline 3. DOSI & 0.898 & 0.761 & 0.900 & 0.844 & 0.914 & 0.727 & 0.875 \\
\hline 4. SOSI & 0.880 & 0.923 & 0.944 & - & 0.940 & 0.839 & 0.905 \\
\hline 5. POSI & 0.906 & 0.915 & 0.933 & - & 0.942 & 0.843 & 0.907 \\
\hline
\end{tabular}

FFC: Face to Face Communication

PSP: Penetration in Surrounding People

DOSI: Depth of Online Social Interaction

SOSI: Satisfaction of Offline Social Interaction

POSI: Preference for Online Social Interaction

Figure 2 shows the results of SEM analyses.

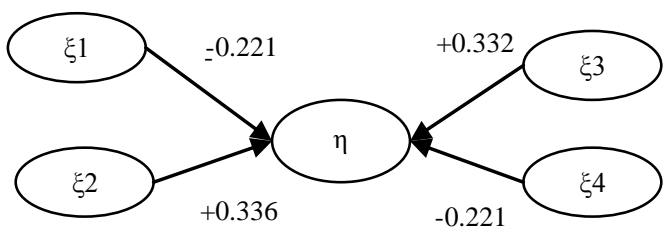

$\xi 1$ - Face to face communication, $\xi 2$ - Penetration in surrounding people,

$\xi 3$ - Depth of online social interaction, $\xi 4$ - Satisfaction of offline social

interaction, $\eta$ - Preference for online social interaction, under the conditions: $\mathrm{P}=0.05,|\mathrm{~T}|>1.96$.

Figure 2. Factors' Weights of Conceptual Model

The first hypothesis dealt with the relationship between face to face communication and the preference for online social interaction. After controlling for other factors, level of good at face to face communication had a significantly and negatively influence on preference for social interaction $(b=-0.221, T=-3.9246)$. Thus, the first hypothesis was supported.

The second hypothesis dealt with the relationship between the penetrations of crowd around and the preference for online social interaction. After controlling for other factors, level of penetration crowd around significantly and positively influenced preference for social interaction $(b=0.336, T=6.5571)$. Thus, the second hypothesis was supported.

For the third hypothesis, after controlling for other factors, the depth of online social interaction significantly and positively influenced preference for social interaction $(b=0.332, T=6.5643)$. Therefore, the third hypothesis was supported.

The last hypothesis dealt with the relationship between the satisfaction of offline social interaction and the preference for online social interaction. After controlling for other factors, level of satisfaction of offline social interaction had a significantly and negatively influence on preference for social interaction $(b=-0.221, T=-3.1906)$. Thus, the forth hypothesis was supported.

\section{CONCLUSIONS}

Social activities are basic human activities. With the development of mobile internet technology and intelligent terminals, online social interaction will become more and more common. It will not only as a supplement for traditional social interaction, but also increasingly becoming an important part of social interaction (Cheung \& Lee, 2010) [3]. What factors may influence an individual's preference for online social interaction? In this paper, we supposed 4 Hypotheses and had an empirical study to consider the influencing factors of preference for online social interaction in both online and offline 
environment. Finally, we found that: 1) compared to those who were good at face-to-face communication, individuals who were not might prefer online social interaction much more; 2) the higher the popularity level of preference for online social interaction among the crowd around an individual, the more he was likely to show similar preference; 3) compared to those with a limited level of involvement in online social interaction, individuals with a higher level would develop a stronger preference for online social interaction; 4) compared to those with a higher level of satisfaction with their current offline contacts, individuals with a lower level of satisfaction were more likely to prefer online social interaction. These findings will give some help for users and designers of social networking sites

\section{REFERENCES}

[1] D. E. Wittkower. "Facebook and Philosophy: What's on Your mind?" Opencourt: Chicago, pp. 14-15, 2010.

[2] D. M. Boyd, N. B. Ellison. "Social Network Sites: Definition, History, and Scholarship". Engineering Management Review, 38(3), pp. 16-31, 2010.

[3] C. M. Cheung, M. K. Lee. "A Theoretical Model of Intentional Social Action in Online Social Networks". Decision Support Systems, 49(1), pp. 24-30, 2010.

[4] S. E. Caplan. "Challenging the Mass-Interpersonal Communication Dichotomy: Are We Witnessing the Emergence of an Entirely New Communication System". Electronic Journal of Communication, 11(1), pp. 111-116, 2001.

[5] S. E. Caplan. "Preference for Online Social Interaction: A Theory of Problematic Internet Use and Psychosocial Well-Being". Communication Research, 30(6), pp. 625-648, 2003.

[6] S. L. Crites, L. R. Fabrigar, R. E. Petty. "Measuring the Affective and Cognitive Properties of Attitudes: Conceptual and Methodological Issues". Personality and Social Psychology Bulletin, 20(6), pp. 619-634, 1994.

[7] K. W. Beard, E. M. Wolf. "Modification in the Proposed Diagnostic Criteria for Internet Addiction". Cyber Psychology \& Behavior, 4(3), pp. 377-383, 2001.

[8] R. A. Davis. "A Cognitive-Behavioral Model of Pathological Internet Use". Computers in Human Behavior, 17(2), pp. 187-195, 2001.

[9] C. M. Ridings, D. Gefen. "Virtual Community Attraction: Why People Hang out Online." Journal of Computer Mediated Communication, 10(1), pp. 00-00, 2004.

[10] X. Z. Xie, Y. Zhang. "Research of Online Social Communication in China". Library and Information Service, 55(6), pp. 16-19, 2011. ( in Chinese)

[11] G. Fioravanti, D. Dèttore, S. Casale. "Adolescent Internet Addiction: Testing the Association Between Self-Esteem, the Perception of Internet Attributes, and Preference for Online Social Interactions". Cyber psychology, Behavior, and Social Networking, 15(6), pp. 318-323, 2012.

[12] S. Casale, L. Tella, "Fioravanti G. Preference for Online Social Interactions among Young People: Direct and Indirect Effects of Emotional Intelligence". Personality and Individual Differences, 54(4), pp. 524-529, 2013.
[13] J. Bonds-Raacke, J. Raacke. "MySpace and Facebook: Identifying Dimensions of Uses and Gratifications for Friend Networking Sites". Individual Differences Research, 8(1), pp. 27, 2010.

[14] T. Ryan, S. Xenos. "Who uses Facebook? An Investigation into the Relationship between the Big Five, Shyness, Narcissism, Loneliness, and Facebook Usage". Computers in Human Behavior, 27(5), pp. 1658-1664, 2011.

[15] G. Rachel, I. Michaelle, W. Kate, et al.. "Face-to-Face or Facebook: Can Social Connectedness be Derived Online?" Computers in Human Behavior, (29), pp. 604-609, 2013.

[16] Z. F. Zhang, Q. D. Li, "Latent Friend Recommendation in Social Network Services". Journal of the China Society for Scientific and Technical Information, 30(12), pp. 1319-1325, 2011. (in Chinese)

[17] Y. Yu, G. H. Qiu, S. Li. "Analysis of Interaction Pattern in Social Networking Sites". Journal of the China Society for Scientific and Technical Information, 31(2), pp. 213-224, 2012. ( in Chinese)

[18] Z. H. Deng, Y. S. Zhao, M. S. Yang. "Research on Social Communication Demand Model and its System Implementation". Journal of the China Society for Scientific and Technical Information, 31(12), pp. 1305-1303, 2012. (in Chinese)

[19] X. B. Tang, S. Zhang. "A Personalized Recommendation System of Online Social Networks". Information Studies: Theory \& Application, 36(2), pp. 91-95, 2013.( in Chinese)

[20] Y. Amichai-Hamburger, A. Furnham. "The Positive Net". Computers in Human Behavior, 23(2). pp. 1033-1045, 2007.

[21] S. E. Caplan. "A Social Skill Account of Problematic Internet Use". Journal of Communication, 55(4), pp. 721-736, 2005.

[22] S. E. Caplan. "Relations among Loneliness, Social Anxiety, and Problematic Internet Use". Cyber Psychology \& Behavior, 10(2), pp. 234-242, 2006.

[23] J. B. Walther. "Computer-Mediated Communication Impersonal, Interpersonal and Hyper Personal Interaction". Communication Research, 23(1), pp. 3-43, 1996.

[24] A. Bandura, D. C. McClelland. "Social Learning Theory". General Learning Press: New York, pp. 33-46. 1977.

[25] R. F. Baumeister, M. R. Leary. "The Need to Belong: Desire for Interpersonal Attachments as a Fundamental Human Motivation". Psychological Bulletin, 117(3), pp. 497, 1995.

[26] J. Klick, F. Parisi. "Social Networks, Self-Denial, and Median Preferences: Conformity as an Evolutionary Strategy". Journal of Socio-Economics, 37(4), pp. 1319-1327, 2008.

[27] R. P. Bagozzi. "The Legacy of the Technology Acceptance Model and a Proposal for a Paradigm Shift". Journal of the Association for Information Systems, 8(4), pp. 3, 2007.

[28] B. W. Lee, L. A. Stapinski. "Seeking Safety on the Internet: Relationship between Social Anxiety and Problematic Internet Use". Journal of Anxiety Disorders, 26(1), pp. 197-205, 2012.

[29] S. E. Caplan. "Theory and Measurement of Generalized Problematic Internet Use: A Two-Step Approach". Computers in Human Behavior, 26(5), pp. 1089-1097, 2010.

[30] K. Subrahmanyam, P. Greenfield. "Online Communication and Adolescent Relationships". The Future of Children, 18(1), pp. 119146, 2008.

[31] J. W. Turner, J. A. Grube, J. Meyers. "Developing an Optimal Match within Online Communities: An Exploration of CMC Support Communities and Traditional Support". Journal of Communication, 51(2), pp. 231-251, 2006.

[32] R. A. Bell, X. Hu, S. E. Orrange, et al. "Lingering Questions and Doubts: Online Information-Seeking of Support Forum Members Following Their Medical Visits". Patient Education and Counseling, 85(3), pp. 525-528, 2011. 